\title{
Reproductive strategies and population genetic structure of Fucus spp. across a northeast Atlantic biogeographic transition ${ }^{\text {is }}$
}

\author{
Susana C. Almeida ${ }^{1, *}$, Katy R. Nicastro ${ }^{1}$, Gerardo I. Zardi ${ }^{2}$, Gareth A. Pearson ${ }^{1}$, Myriam Valero ${ }^{3}$ and \\ Ester A. Serrão ${ }^{1}$ \\ ${ }^{1}$ CCMAR, Centro de Ciências do Mar, Universidade do Algarve, Campus de Gambelas, 8005-139 Faro, Portugal \\ 2 Department of Zoology and Entomology, Rhodes University, Grahamstown 6140, South Africa \\ ${ }^{3}$ UMI 3614, CNRS, UPMC, PUC, UACH, Station Biologique de Roscoff, CS 90074, 29688 Roscoff, France
}

Received 16 October 2016 / Accepted 8 March 2017

\begin{abstract}
Geographical discontinuities in the composition of species assemblages are often mirrored by genetic clines and local adaptation in species that extend across such biogeographic disjunction. Species distributed across such biogeographic discontinuities are thus more prone to develop genetic clines and adaptations to environmental variation. The northwest coast of France encompasses a biogeographic boundary between cold- and warm-temperate marine ecosystems. Distinct hydrographic features characterize northern and southern shores, promoting physical oceanographic breaks that can affect dispersal and connectivity between populations. Furthermore, mosaics of contrasting conditions may affect local patterns of species assemblages and potential adaptive pressures. Along this stretch of coast, the intertidal habitat is largely dominated by brown algae of the genus Fucus, key structuring species common along North Atlantic shorelines. Fucus spiralis, F. guiryi and F. vesiculosus are sister species with different mating systems. They have extensive sympatric geographical distributions and distinct but overlapping vertical distributions in the intertidal zone. We examined genetic structure and diversity across this major environmental transition zone using neutral microsatellite markers to investigate patterns of differentiation between populations of each species inhabiting the two different biogeographic regions. We found contrasting results between the dioecious species (F. vesiculosus) and the two selfing hermaphroditic lineages (F. spiralis and F. guiryi). Genetic differentiation of northern and southern populations of $F$. vesiculosus followed the expectation from a hypothetical oceanographic discontinuity across this biogeographical transition zone, but this was not the case for the two hermaphroditic species. The former had higher genetic diversity and structure along the distribution range investigated whereas selfing hermaphrodites had less variability and were not geographically structured. Our results suggest that genetic patterns are correlated with this biogeographical transition zone but this effect is dependent on mating system, a determining factor affecting population structure. Additionally, other factors such as intertidal elevation may also play a role in observed difference in genetic structuring.
\end{abstract}

Keywords: Genetic diversity / Microsatellites / Fucus / Biogeographic transition zones / Mating system

\section{Introduction}

Biogeographic transitions are areas where different physical and environmental conditions and ecological factors lead to significant changes in species assemblages. Hence, species living throughout these environmental discontinuities are more prone to genetic clines, although they do not necessarily show consistent structuring (Lima et al., 2007;

\footnotetext{
Supporting information is only available in electronic form at www.alr-journal.org.

* Corresponding author: sue.c.almeida@gmail.com
}

Neiva et al., 2012, 2016; Guillemin et al., 2016). These regions represent ideal settings for the investigation of species limits, range shifts and adaptations to changes in environmental conditions (Martinez et al., 2012; Assis et al., 2014; Robuchon et al., 2014). Transition zones can be reflected in dissimilarities in the genetic background throughout the continuum of a species' distribution. In marine ecosystems, these are generally attributed to dispersal barriers (e.g. currents, upwelling) that may limit along-shore dispersal, to environmental discontinuities acting through divergent natural selection or to reproductive strategies promoting self-recruitment (Gilg and Hilbish, 2003; Selkoe et al., 2010). Major biogeographic boundaries have been identified and associated with genetic 
breaks for several species, particularly coastal ones (e.g. fishes, Williams and Benzie, 1998; marine invertebrates, Haye et al., 2014; seaweeds, Tellier et al., 2009; Zardi et al., 2015a). Hence, these regions represent ideal settings for the investigation of species limits, range shifts and adaptations to changes in environmental conditions (Pujol et al., 2009; Martinez et al., 2012; Provan, 2013; Assis et al., 2014; Leys et al., 2014; Robuchon et al., 2014).

A biogeographic boundary between cold- and warmtemperate marine ecosystems is found on the northwest coast of France (Jolly et al., 2005; Gallon et al., 2014). This stretch of coast outlines the transition between the Celtic Sea and the South European Atlantic Shelf ecoregions which belong to distinct cohesive units, the Northern European Seas and the Lusitanian provinces, respectively (Spalding et al., 2007). At the northwest endpoint of Brittany, in the Ushant front, the Gulf Stream diverts into two main trajectories, one flowing South, in the direction of the Bay of Biscay, and one towards the English Channel (Billot et al., 2003). Distinct hydrographic features characterize northern and southern shores. Hydrodynamics on the southern coast are characterized by several mesoscale structures such as low salinity lenses, river plumes and fronts (Ayata et al., 2011). Additionally, upwelling occurs south of the Brittany peninsula (north of Bay of Biscay), linked to favorable westerly and northwesterly winds and weak tidal currents (Puillat et al., 2004, 2006). On the north coast of Brittany, eddies and diverted circulation related to the complex topography of the rocky shore characterize near shore hydrodynamics (Salomon and Breton, 1993; Billot et al., 2003).

This biogeographic discontinuity is coincident with distributional limits for a number of taxa (Breeman, 1988; Lüning, 1990). The study of this unique region is thus important to understand the contribution of both environmental factors (present and past) and life-history traits influencing species distribution (Engel et al., 2004; Mieszkowska and Sugden, 2016).

The intertidal habitat of this coastline is largely dominated by brown algae belonging to the genus Fucus. These form a group of dominant structuring species with wide geographic ranges along North Atlantic shorelines (Coyer et al., 2006; Hoarau et al., 2007; Billard et al., 2010). Fucus spiralis, F. guiryi and $F$. vesiculosus are genetically closely related, belonging to the same phylogenetic clade (Cánovas et al., 2011; Zardi et al., 2011). They are characterized by distinct mating systems (Zardi et al., 2011). These three species have extensive sympatric distributions and, of the three, only $F$. guiryi extends further south on the open coast along southern Iberia and Morocco (Zardi et al., 2015b), where $F$. vesiculosus also occurs but only inside estuaries and coastal lagoons (Ladah et al., 2003). When in sympatry, they are vertically zoned (Billard et al., 2010 where F. guiryi was named F. spiralis low; Zardi et al., 2011). On the upper shore $F$. spiralis occurs above $F$. guiryi, both selfing hermaphroditic species. The dioecious $F$. vesiculosus occurs lower in the intertidal (Zardi et al., 2011). Importantly, the distribution and the abundance of these species at the southern range have been affected by ongoing climate change (Nicastro et al., 2013; Lourenço et al., 2016), and future range shifts are predicted (Assis et al., 2014), highlighting the significance of understanding population genetic structure, environmental determinants and their variability.
Here, we examine the genetic structure and genetic diversity of three sister species of macroalgae across a known marine biogeographic transition zone in northwest France. Specifically, we applied a population genetic approach using seven microsatellite markers to investigate differentiation patterns between populations of each species inhabiting the two different biogeographic regions. We also aim to infer the possible influence of mating system on population structure along this region, by choosing model species with distinct reproductive modes (selfing hermaphrodites versus dioecious species).

\section{Methods}

Samples were collected between March 2009 (populations of Roscoff and Dossen) and February 2012 (populations of Le Havre, St. Malo, Larmore and Cotinière). Collection was based on morphometric identification (Zardi et al., 2011) and position on the shore (Table 1). Individuals were sampled approximately $2 \mathrm{~m}$ apart to avoid partially, overlapping zones (Zardi et al., 2011) and any intermediate morphotype.

\subsection{DNA extraction and microsatellite amplification}

Total DNA was extracted from 5 to $10 \mathrm{mg}$ of dried tissue using the CTAB method as in Coyer et al. (2009). Seven microsatellite loci (Engel et al., 2003; Wallace et al., 2004; Coyer et al., 2009) were used. Polymerase Chain Reactions (PCR) were performed with a Thermal Cycler 2720 (Applied Biosystems) following conditions detailed in Table S1. The lengths of PCR products were analysed on an automated sequencer ABI PRISM 3130 (Applied Biosystems) using as size standards 350 ROX (L20, L38, L58, L78, L94, F12) and 500 LIZ (F26II, F42) on the software GeneScan. Raw allele sizes were scored using STRand (Toonen and Hughes, 2001) and binned into allele classes with MsatAllele R (Alberto, 2009).

\subsection{Data analyses}

All analyses were conducted for each species independently. Presence of null alleles and scoring errors were tested with MicroChecker (van Oosterhout et al., 2004). Allelic richness (Â) was estimated and standardised to the smallest sample size within each species $(n=30, n=31$ and $n=22$ for $F$. guiryi, $F$. spiralis and $F$. vesiculosus, respectively) using StandArich $\mathrm{R}$ (Alberto et al., 2006). Nei's gene diversity (unbiased expected heterozygosity, $H_{\mathrm{E}}$; Nei, 1978) and observed heterozygosity $\left(H_{\mathrm{O}}\right)$ were estimated with GENETIX 4.05 (Belkhir et al., 2004) and used on tests of departure from random mating within each population. Significance of $F_{\text {IS }}$ was estimated after $10^{4}$ permutations with GENETIX 4.05 (Belkhir et al., 2004).

Genetic differentiation between pairs of populations was calculated across loci with the $F_{\mathrm{ST}}$ estimator $(\theta)$ (Weir and Cockerham, 1984). Significance was tested with $10^{4}$ random permutations using a threshold adjusted and $q$-value correction for multiple comparisons (Storey, 2002). Patterns of genetic structure were depicted through Factorial Correspondence Analysis (FCA) of individual allelic frequencies. All the above analyses were performed using GENETIX 4.05 (Belkhir et al., 2004). Pairwise genetic differentiation was also estimated with $D_{\text {Jost }}$ (Jost, 2008) using R package DEMEtics 
Table 1. Genetic diversity parameters for (A) Fucus spiralis, (B) F. guiryi and (C) F. vesiculosus. Sampled locations and codes, coordinates, number of individuals $(N)$, unbiased gene diversity $\left(H_{\mathrm{E}}\right)$, observed heterozygosity $\left(H_{\mathrm{O}}\right)$, inbreeding coefficient multilocus estimates $\left(F_{\mathrm{IS}}\right)$, allelic richness standardized for the smallest sample size $(\hat{\mathrm{A}})$, standard deviation $\left.(\mathrm{SD}) .{ }^{*}\right)$ Significant deviation from Hardy-Weinberg expectations with $q$-value correction for multiple comparisons $(q$-value $<0.01)$.

\begin{tabular}{|c|c|c|c|c|c|c|c|}
\hline Location & Latitude & Longitude & $\mathbf{N}$ & $\mathrm{H}_{\mathrm{E}}$ & $\mathrm{H}_{\mathrm{O}}$ & $F_{\text {IS }}$ & $\hat{A} \pm S D$ \\
\hline Le Havre (LH) & $49^{\circ} 38^{\prime} 26.95^{\prime \prime N}$ & $0^{\circ} 08^{\prime} 54.47^{\prime \prime} \mathrm{E}$ & 32 & 0.068 & 0.018 & $0.741^{*}$ & $1.14 \pm 0$ \\
\hline St. Malo (SM) & $48^{\circ} 39^{\prime} 10.75^{\prime \prime} \mathrm{N}$ & $2^{\circ} 01^{\prime} 49.95^{\prime \prime} \mathrm{W}$ & 32 & 0.046 & 0.013 & $0.709^{*}$ & $1.29 \pm 0$ \\
\hline Roscoff (RF) & $48^{\circ} 43^{\prime} 41.14^{\prime \prime} \mathrm{N}$ & $3^{\circ} 59^{\prime} 17.69^{\prime \prime} \mathrm{W}$ & 32 & 0.103 & 0.040 & $0.613^{*}$ & $1.97 \pm 0.08$ \\
\hline Dossen (DS) & $48^{\circ} 42^{\prime} 15.27^{\prime \prime} \mathrm{N}$ & $4^{\circ} 04^{\prime} 18.73^{\prime \prime} \mathrm{W}$ & 31 & 0.091 & 0.014 & $0.851^{*}$ & $1.43 \pm 0$ \\
\hline Larmore (LA) & $47^{\circ} 42^{\prime} 02.11^{\prime \prime} \mathrm{N}$ & $3^{\circ} 23^{\prime} 11.21^{\prime \prime} \mathrm{W}$ & 31 & 0.206 & 0.018 & $0.912^{*}$ & $1.86 \pm 0$ \\
\hline
\end{tabular}

\begin{tabular}{|c|c|c|c|c|c|c|c|}
\hline Location & Latitude & Longitude & $\mathbf{N}$ & $\mathrm{H}_{\mathrm{E}}$ & $\mathrm{H}_{\mathrm{O}}$ & $\mathrm{F}_{\mathrm{IS}}$ & $\hat{A} \pm S D$ \\
\hline St. Malo (SM) & $48^{\circ} 39^{\prime} 10.75^{\prime \prime} \mathrm{N}$ & $2^{\circ} 01^{\prime} 49.95^{\prime \prime} \mathrm{W}$ & 32 & 0.009 & 0.000 & $1.000^{\star}$ & $1.13 \pm 0.04$ \\
\hline Roscoff (RF) & $48^{\circ} 43^{\prime} 41.14^{\prime \prime} \mathrm{N}$ & $3^{\circ} 59^{\prime} 17.69^{\prime \prime} \mathrm{W}$ & 30 & 0.153 & 0.067 & $0.570^{*}$ & $3.57 \pm 0$ \\
\hline Dossen (DS) & $48^{\circ} 42^{\prime} 15.27^{\prime \prime} \mathrm{N}$ & $4^{\circ} 04^{\prime} 18.73^{\prime \prime} \mathrm{W}$ & 30 & 0.019 & 0.010 & $0.498^{*}$ & $1.43 \pm 0$ \\
\hline Larmore (LA) & $47^{\circ} 42^{\prime} 02.11^{\prime \prime N}$ & $3^{\circ} 23^{\prime} 11.21^{\prime \prime} \mathrm{W}$ & 32 & 0.087 & 0.009 & $0.899^{*}$ & $1.43 \pm 0$ \\
\hline Cotinière (CT) & $45^{\circ} 54^{\prime} 54.64^{\prime \prime} \mathrm{N}$ & $1^{\circ} 20^{\prime} 00.03^{\prime \prime} \mathrm{W}$ & 31 & 0.031 & 0.005 & $0.853^{*}$ & $1.29 \pm 0$ \\
\hline
\end{tabular}

\begin{tabular}{cccccccc} 
(C) & \multicolumn{1}{l}{} \\
\hline Location & Latitude & Longitude & $\mathbf{N}$ & $\mathrm{H}_{\mathrm{E}}$ & $\mathrm{H}_{\mathrm{O}}$ & $\mathrm{F}_{\text {IS }}$ & $\hat{A} \pm$ SD \\
\hline Roscoff (RF) & $48^{\circ} 43^{\prime} 41.14^{\prime \prime} \mathrm{N}$ & $3^{\circ} 59^{\prime} 17.69^{\prime \prime} \mathrm{W}$ & 32 & 0.735 & 0.603 & $0.182^{*}$ & $8.57 \pm 0.3$ \\
Dossen (DS) & $48^{\circ} 42^{\prime} 15.27^{\prime \prime} \mathrm{N}$ & $4^{\circ} 04^{\prime} 18.73^{\prime \prime} \mathrm{W}$ & 31 & 0.701 & 0.590 & $0.160^{*}$ & $6.50 \pm 0.3$ \\
Larmore (LA) & $47^{\circ} 42^{\prime} 02.11^{\prime \prime} \mathrm{N}$ & $3^{\circ} 23^{\prime} 11.21^{\prime \prime} \mathrm{W}$ & 22 & 0.679 & 0.630 & 0.074 & $6.71 \pm 0$ \\
\hline
\end{tabular}

(Gerlach et al., 2010). Significance was tested with $10^{4}$ bootstrap resamplings and $p$-value correction for multiple comparisons with the Benjamini and Hochberg (1995) method. Additionally, confidence intervals were calculated for both estimators of genetic differentiation with R package diveRsity (Keenan et al., 2013).

The question of whether there are distinct genetic clusters, their number $(K)$ and the assignment of individual multilocus genotypes to those clusters were performed for F. vesiculosus using STRUCTURE (Pritchard et al., 2000). Analyses were performed for $K$ ranging from 1 to 4 (number of locations plus one) without any prior population assignment, with correlated allele frequencies assumed and admixture allowed. For each $K$, ten independent runs were performed using a burning length of $5 \times 10^{4}$ iterations and $1 \times 10^{4}$ Markov Chain Monte Carlo (MCMC) iterations. The most likely number of genetic clusters was selected based on $\Delta K$ (Evanno et al., 2005) implemented in Structure Harvester (Earl and von Holdt, 2012).

\section{Results}

\subsection{Genetic diversity and mating system}

Null alleles at high frequencies $(>0.2)$ were detected for F26II (Fig. S1) and thus, to avoid an overestimation of $F_{\text {IS }}$ and $F_{\mathrm{ST}}$ estimators (Chapuis and Estoup, 2007), this locus was removed from all subsequent analyses.

A total of 132 distinct alleles were obtained from the 398 individuals genotyped. Different levels of polymorphism were observed among loci, ranging from 1 to 20 alleles per locus. Fucus spiralis was the least polymorphic species (monomorphic for loci L38 and L58) and the highest (3-20 alleles per locus) was $F$. vesiculosus. Loci L20 and F12 showed the highest numbers of alleles (30) for all species, compared to all other loci (Fig. S2).

Gene diversity and allelic richness of $F$. spiralis were low and very similar across locations $\left(H_{\mathrm{E}}: 0.046-0.206\right.$; $\hat{\mathrm{A}}$ : 1.14-1.97, Table 1A). Diversity was also low in F. guiryi $\left(H_{\mathrm{E}}\right.$ : $0.009-0.153$; Â: 1.13-3.57, Table 1B), with the highest values in Roscoff. In contrast, F. vesiculosus had much higher genetic diversity across all sites compared to the other species ( $H_{\mathrm{E}}: 0.679-0.735 ; \hat{\mathrm{A}}: 6.50-8.57$, Table 1C).

With the exception of $F$. vesiculosus in Larmore, $F_{\text {IS }}$ values (Table 1) were significantly positive (heterozygote deficit) for all species and locations, with much higher estimates for both hermaphroditic species (F. spiralis and $F$. guiryi) than for $F$. vesiculosus.

\subsection{Population genetic structure and biogeographic patterns}

The distribution of genetic variation, as illustrated by Factorial Correspondence Analysis, revealed distinct patterns between species.

Populations of the species $F$. spiralis, revealed in the FCA plot (Fig. 1B) some overlapping between individuals belonging to different locations (Le Havre, St. Malo and Dossen), associated with low genetic variability and equal allele size 

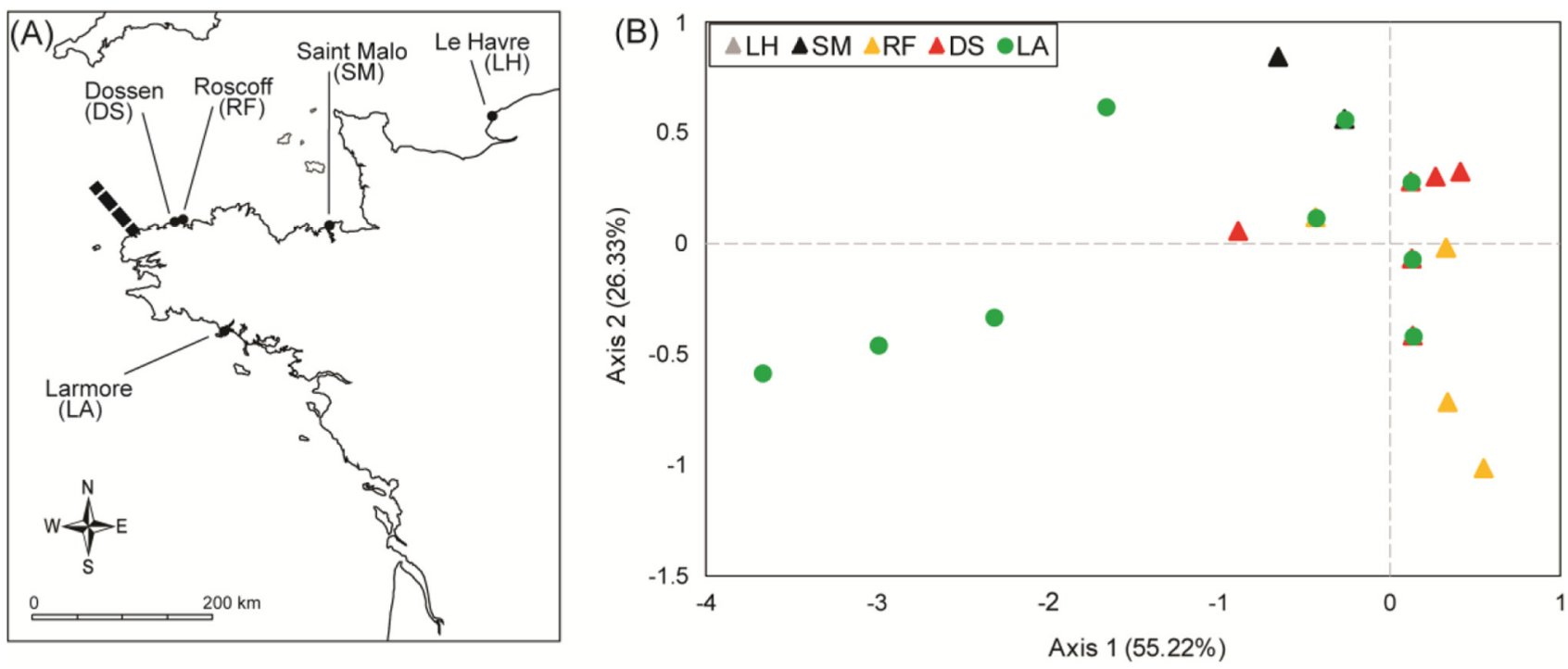

Fig. 1. Sampling locations and genetic structure for Fucus spiralis. (A) Map of the study area; dots indicate sampled locations; code of each site is in brackets; the biogeographic discontinuity is indicated by a dashed line, following Ayata et al. (2010) and Gallon et al. (2014). (B) Factorial Correspondence Analysis (FCA) based on allele frequencies at four microsatellite loci. Percentages of inertia are shown between parentheses for each axis.

at these locations. Conversely, Larmore displayed the highest distribution of individuals along the second axis, corresponding to the highest variance in allele frequencies within this location (Fig. S2). This was further illustrated by low levels of pairwise genetic differentiation parameters, particularly $D_{\mathrm{EST}}$ estimates (Table 2A).

For F. guiryi, the first axis of the FCA, which describes the highest variance between populations $(72.23 \%)$, delimited the southern locations of Larmore and Cotinière (Fig. 2B) but all other locations did not retrieve any pattern of genetic structure. In addition, Roscoff exhibited a scattered distribution throughout the second axis of the FCA plot. This was further supported by pairwise estimates of genetic differentiation which were low for comparisons between all locations with the exception of Roscoff (Table 2B). The first axis of the FCA, which describes the highest variance between populations $(36.61 \%)$, distinguished the northern from the southern locations (Fig. 2B).

The populations of $F$. vesiculosus comprised two clusters that were clearly geographically structured between northern and southern Brittany. The Bayesian analyses implemented in STRUCTURE revealed two genetic groups (Fig. S3) that were geographically consistent with a biogeographic boundary. This pattern was also reflected in the FCA plot (Fig. 3B) and in both of the pairwise genetic differentiation estimators, $F_{\mathrm{ST}}$ and $D_{\mathrm{EST}}$ (Table 2C).

\section{Discussion}

\subsection{The Brittany biogeographic transition zone}

The hypothesis that the biogeographic transition zone between southern and northern Brittany would influence genetic structure of the three distinct fucoid species was rejected for the selfing hermaphroditic species, which showed very low diversity across the entire study area, but was supported by the patterns observed for the dioecious species. The very distinct levels of genetic diversity found on the northwest coast of France between the dioecious Fucus vesiculosus and the much less diverse hermaphroditic species, F. spiralis and F. guiryi, suggest highly contrasting strategies for population persistence and colonization, between these sister species.

The division between northern and southwestern populations observed for $F$. vesiculosus agrees with the zonation of the marine biogeographical provinces in the northeastern Atlantic Ocean (Spalding et al., 2007). Genetic patterns reflecting this physical geographic discontinuity region have been previously observed for sessile species, such as invertebrates (Goldson et al., 2001; Jolly et al., 2005), kelps (Couceiro et al., 2013) and fucoids (Neiva et al., 2012) and patterns of genetic differentiation have been correlated to surface currents in the region. Genetic differentiation patterns separating northern and southern Brittany have been associated with the major current trajectories flowing in the region following divergence in the Ushant front. However, a few exceptions exist to the concordance between genetic and largescale physical patterns (e.g. kelps, Billot et al., 2003). In fact, local turbulence regimes created by the convoluted topography of the Brittany coast may be more important in coastal species and dilute the contribution from this major current regime (Billot et al., 2003). Moreover, currents in the English Channel are highly variable in intensity and orientation (Salomon and Breton, 1993) and thus, this may lead to significant divergence in local patterns, particularly on the northern coast, that prevail or overcome the large-scale dominant current pattern. This could possibly explain the genetic structuring features of both hermaphroditic species.

Note that two possible bias may explain such a pattern of genetic structure. First, the clearer pattern of genetic differentiation between northern and southwestern populations observed for $F$. vesiculosus could also be explained by a cumulative effect of spatial and temporal genetic differentiation since the 
Table 2. Pairwise genetic differentiation for (A) Fucus spiralis, (B) F. guiryi and (C) F. vesiculosus. Mean values of $F_{\mathrm{ST}}$ with the estimator $\theta$ are reported above the diagonal, while mean $D_{\text {Jost }}$ values are reported below the diagonal. Asterisks indicate significant deviation from null expectations with $q$-value correction for multiple comparisons: $*<0.05 ; * *<0.01 ; * * *<0.001 .95 \%$ confidence intervals are in brackets. Codes correspond to locations in Table 1.

A.

\begin{tabular}{lccccc}
\multicolumn{1}{c}{} & LH & SM & RF & DS & LA \\
\cline { 2 - 6 } LH & & $0.4248^{* * *}$ & 0.0278 & 0.0722 & $0.0735^{*}$ \\
& & $(0.2095,0.6288)$ & $(-0.0432,0.1966)$ & $(-0.0456,0.2829)$ & $(-0.0179,0.2156)$ \\
SM & $0.0081^{* *}$ & & $0.2100^{\star * *}$ & $0.1627^{\star *}$ & $0.1432^{\star * *}$ \\
& $(0.0038,0.0128)$ & & $(0.0548,0.3768)$ & $(0.0194,0.3487)$ & $(0.0437,0.2905)$ \\
RF & $0.0009^{*}$ & $0.0041^{* *}$ & & 0.0001 & 0.0247 \\
& $(-0.0006,0.0043)$ & $(0.0008,0.0081)$ & & $(-0.0480,0.0815)$ & $(-0.0255,0.1066)$ \\
DS & $0.0018^{*}$ & $0.0030^{* *}$ & 0.0001 & & 0.0266 \\
& $(-0.0007,0.0061)$ & $(0.0003,0.0068)$ & $(-0.0009,0.0026)$ & & $(-0.0250,0.1100)$ \\
LA & $0.0081^{*}$ & $0.0061^{* *}$ & $0.0009^{*}$ & $0.0014^{*}$ & \\
& $(-0.0003,0.0259)$ & $(0.0004,0.0181)$ & $(-0.0036,0.0128)$ & $(-0.0030,0.0127)$ &
\end{tabular}

B.

\begin{tabular}{lccccc}
\multicolumn{1}{c}{} & SM & RF & DS & LA & CT \\
\cline { 2 - 6 } SM & & $0.3292^{\star \star *}$ & 0.0034 & 0.0734 & 0.0091 \\
& & $(0.1688,0.5330)$ & $(-0.0210,0.0530)$ & $(-0.0094,0.1800)$ & $(-0.0364,0.0801)$ \\
RF & $0.0072^{\star *}$ & & $0.2812^{\star \star *}$ & $0.2597^{\star \star *}$ & $0.2980^{\star * *}$ \\
& $(0.0028,0.0123)$ & & $(0.1115,0.4818)$ & $(0.1362,0.4141)$ & $(0.1498,0.4817)$ \\
DS & 0.0001 & $0.0066^{\star *}$ & & $0.0827^{\star}$ & 0.0192 \\
& $(0.0000,0.0004)$ & $(0.0021,0.0116)$ & & $(0.0104,0.1784)$ & $(-0.0208,0.0812)$ \\
LA & $0.0012^{\star *}$ & $0.0091^{* *}$ & $0.0019^{\star *}$ & & 0.0532 \\
& $(-0.0005,0.0058)$ & $(0.0030,0.0181)$ & $(-0.0005,0.0068)$ & & $(-0.0072,0.1421)$ \\
GT & 0.0001 & $0.0073^{\star *}$ & $0.0003^{*}$ & $0.0010^{\star *}$ & \\
& $(-0.0001,0.0007)$ & $(0.0028,0.0125)$ & $(-0.0001,0.0011)$ & $(-0.0006,0.0048)$ &
\end{tabular}

C.

\begin{tabular}{lccc}
\multicolumn{1}{c}{} & RF & DS & LA \\
\cline { 2 - 4 } RF & & $0.0233^{* * *}$ & $0.1303^{* * *}$ \\
& & $(0.0039,0.0480)$ & $(0.0946,0.1727)$ \\
DS & $0.0561^{\star *}$ & & $0.1320^{\star \star *}$ \\
& $(0.0121,0.1066)$ & & $(0.0996,0.1679)$ \\
LA & $0.2217^{\star *}$ & $0.2260^{\star *}$ & \\
& $(0.1423,0.3207)$ & $(0.1570,0.2927)$ &
\end{tabular}

population of Lamore was sampled in 2012 while the two populations from Northern Brittany were sampled in 2009. Second, patterns of genetic structure for hermaphroditic species could also be directly influenced by the low level of polymorphism of the microsatellites used in this study. The set of microsatellites was chosen in order to compare to previous studies for these species (e.g. Coleman and Brawley, 2005; Engel et al., 2005; Billard et al., 2010). Other microsatellites (i.e. more informative) specifically designed for $F$. spiralis (Perrin et al.,
2007) and/or with higher mutation rate could help to improve estimates of the genetic parameters for the hermaphroditic species (Chakraborty et al., 1997; Ellegren, 2004; Engel et al., 2005).

\subsection{Genetic diversity and mating system}

Although all three species showed signs of high inbreeding (heterozygote deficiencies), these were much stronger in 

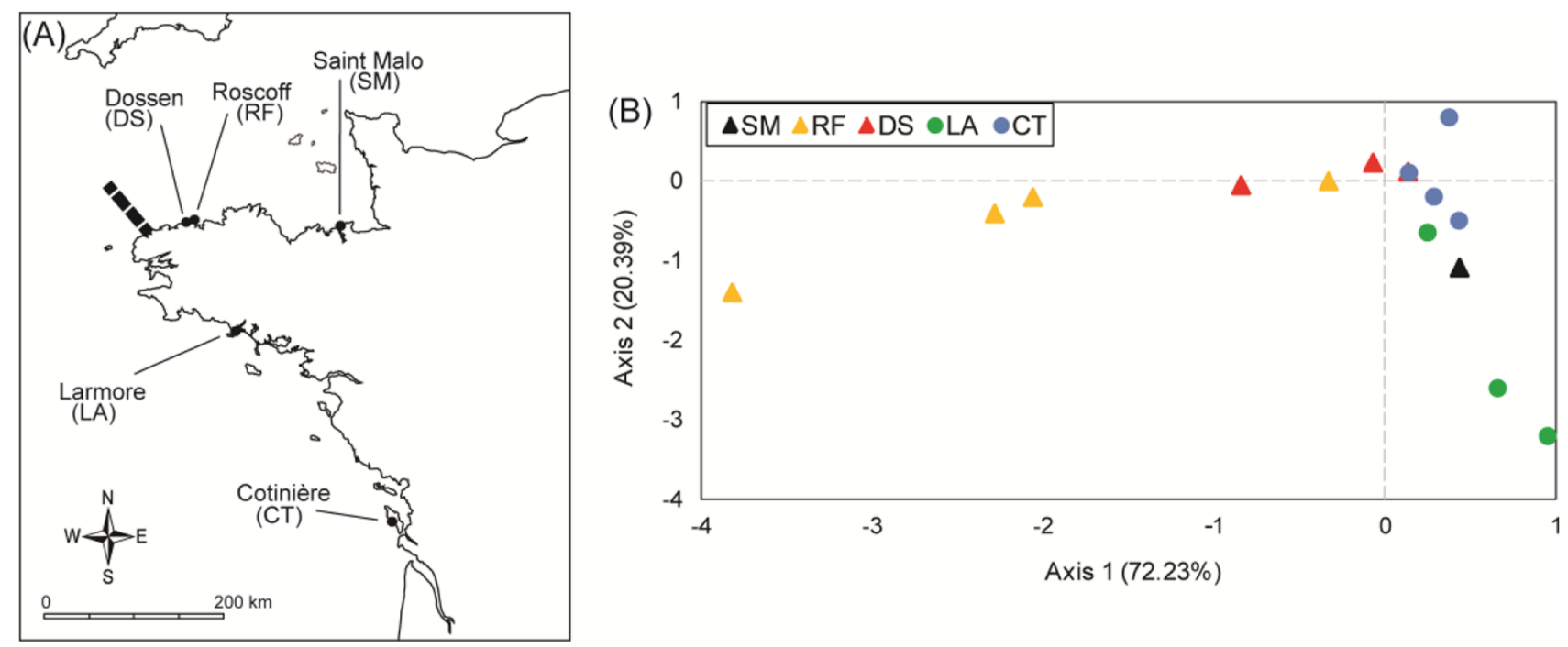

Fig. 2. Sampling locations and genetic structure for Fucus guiryi. (A) Map of the study area; dots indicate sampled locations; code of each site is in brackets; the biogeographic discontinuity is indicated by a dashed line, following Ayata et al. (2010) and Gallon et al. (2014). (B) Factorial Correspondence Analysis (FCA) based on allele frequencies at six microsatellite loci. Percentages of inertia are shown between parentheses for each axis.

the selfing hermaphrodites $F$. spiralis and $F$. guiryi, than in $F$. vesiculosus. This dioecious species also showed high genetic diversity across all sampled locations. This was expected, since the area has been acknowledged as a long term, persistent refugial region for marine species during Quaternary cycles and particularly for $F$. vesiculosus (Assis et al., 2014; reviewed in Neiva et al., 2016).

The differences in genetic diversity among species with different mating system are in accordance with previous studies of these lineages for comparable coastlines using the same molecular markers (Engel et al., 2005; Billard et al., 2010). Heterozygote deficits were expected for the selfing hermaphrodites (Perrin et al., 2007), but have also been consistently observed for $F$. vesiculosus here and in previous studies (Teixeira et al., 2016 and many references therein) throughout the entire European range. Exceptions to this general pattern were found in several of the very isolated southernmost populations in the eastern and western Atlantic (Assis et al., 2014, Teixeira et al., 2016) distributional ranges of $F$. vesiculosus (Muhlin et al., 2008; Muhlin and Brawley, 2009; Assis et al., 2014). Temporal Wahlund effect and limited gamete dispersal were suggested for this pattern (Engel et al., 2005; Teixeira et al., 2016). The genetic background of $F$. vesiculosus has the contribution from several alleles at low frequency; this could result from the mixing of individuals from groups with different allelic frequencies or deriving from genetically differentiated cohorts of recruits, causing a departure from Hardy-Weinberg equilibrium (i.e. Wahlund effect; Johnson and Black, 1984). Alternatively, biparental inbreeding possibly due to short gamete dispersal could also likely explain the significant heterozygosity deficiencies observed (Serrão et al., 1997; Teixeira et al., 2016). Previously, evidence was found for inbreeding depression based on higher heterozygote deficit in recruits than in adults (Teixeira et al., 2016).

Nevertheless, the magnitude of the inbreeding coefficients found for hermaphroditic species could also reflect the contribution of the high proportion of null alleles which was observed for some loci (Fig. S1). Deviations from the HWE may be attributed to both biological factors (e.g. inbreeding, Wahlund effect) and the occurrence of null alleles (Chapuis and Estoup, 2007) and distinguishing the contribution from these two factors is usually based on the evaluation of concordance of patterns across loci (Dakin and Avise, 2004; but see Dharmarajan et al., 2013). The occurrence of null alleles has been acknowledged to inflate values of $F_{\text {IS }}$ (Chybicki and Burczyk, 2009). In our study all polymorphic loci revealed the presence of null alleles for $F$. spiralis, although the same pattern was not observed for $F$. guiryi. Maximum values for the inbreeding coefficient $\left(F_{\text {IS }}=1.0\right)$ were observed for loci with a high proportion of null alleles (L20, F12 and F42 for F. guiryi; L20 and F12 for F. spiralis), and could be considered as a factor contributing to the high inbreeding coefficients observed in the hermaphroditic species.

\subsection{Population genetic structure}

Patterns of genetic structure differed greatly among species, particularly between hermaphroditic and dioecious species. Both hermaphroditic species revealed relatively weak population structuring with variability in allele patterns common across different locations, mainly reflecting the high proportion of fixed alleles present in both species. As reported previously (Engel et al., 2005; where $F$ guiryi was named " $F$. spiralis sympatric"), hermaphroditic species show extremely low polymorphism at all the loci. In contrast, $F$. vesiculosus displayed a clearly distinct clustering pattern that separated northern from southern populations, and a clear differentiation between the three populations that revealed a highly structured distribution of this species in the region.

Differences between species were especially striking between opposite mating systems, suggesting that mating 

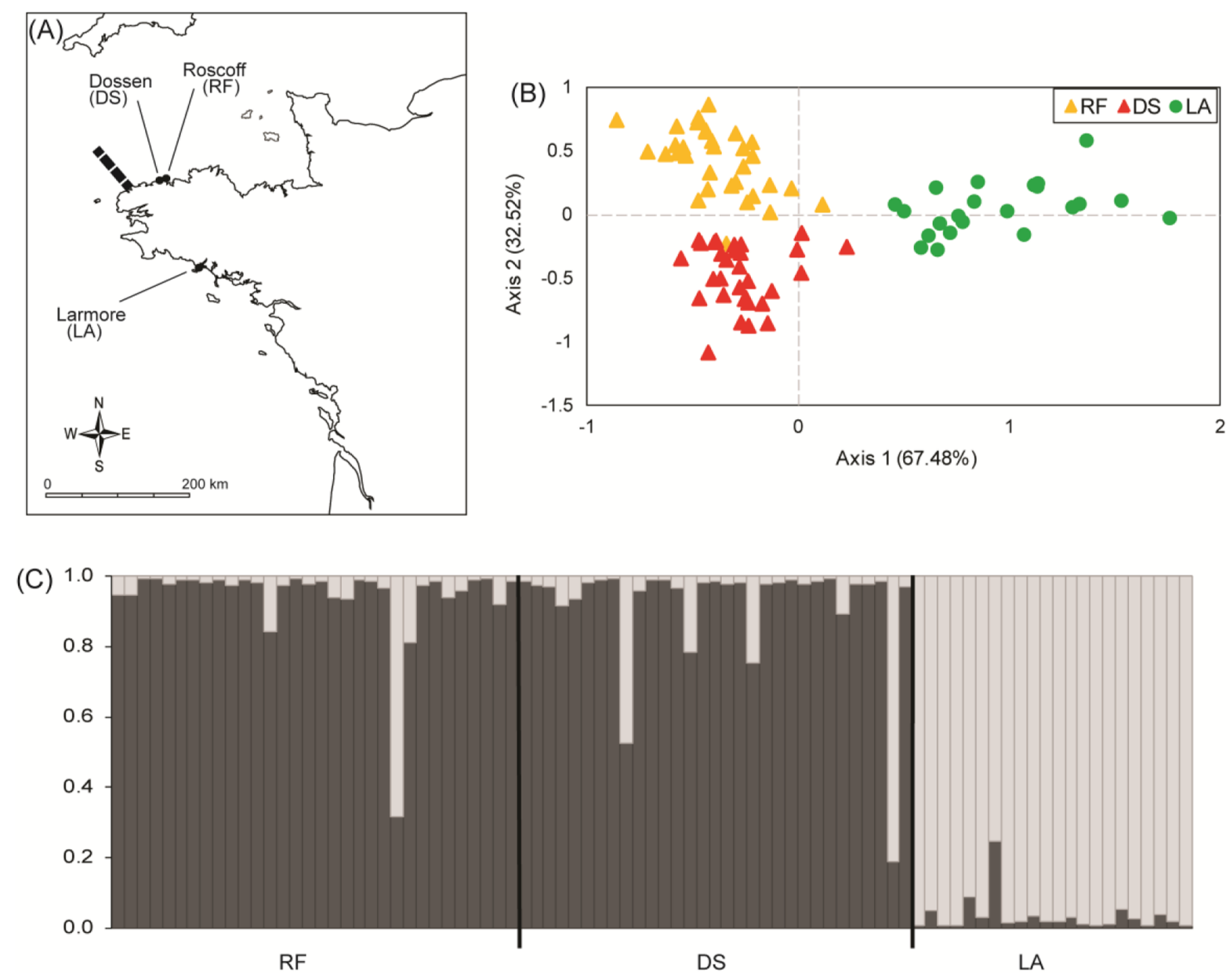

Fig. 3. Sampling locations and genetic structure for Fucus vesiculosus. (A) Map of the study area; dots indicate sampled locations; code of each site is in brackets; the biogeographic discontinuity is indicated by a dashed line, following Ayata et al. (2010) and Gallon et al. (2014). (B) Factorial Correspondence Analysis based on allele frequencies at six microsatellite loci. Percentages of inertia are shown between parentheses for each axis. (C) Genetic subdivision into clusters as defined by STRUCTURE where each vertical bar represents an individual. Proportions of multilocus genotypes for each individual assigned to each $K$ cluster $(K=2)$ is illustrated by different colours. Codes correspond to locations in section $\mathrm{A}$ of this same figure.

system is a major factor explaining the observed patterns. The low population differentiation in the hermaphroditic species were similar to those previously observed for $F$. spiralis in the western Atlantic (Coleman and Brawley, 2005) using the same molecular markers. Low differentiation for $F$. spiralis was previously suggested to reflect a recent colonization history of these populations, with insufficient time for strong genetic differentiation to have evolved (Coleman and Brawley, 2005). Alternatively, large scale dispersal could be possible if extensive episodic recruitment leads to the dominance of one or more age cohorts, which could contribute to the spreading of gametes on scales larger than predicted by life history characteristics alone (Ladah et al., 2003; Coleman and Brawley, 2005). Brief periods of massive gamete release are known to occur in broadcast spawners and have been reported for these species (Monteiro et al., 2012). Moreover, gamete release occurs preferentially during high tide immersion
(Monteiro et al., 2016), reducing spawning opportunities particularly for upper shore species such as $F$. spiralis that live on a narrow stretch of the intertidal area. A short immersion time (18-35\%) (Zardi et al., 2011) for spawning while submerged may increase synchrony and genetic admixture, although the likelihood of selfing counteracts this effect. Alternatively, stochastic factors such as high genetic drift, which is facilitated in selfing hermaphrodites, may also play a role in the genetic patterns observed. Rare alleles are highly prone to genetic drift. With such high proportions of fixed alleles across loci, any new allele with extremely low frequency could (randomly) dictate the overall genetic structuring. Another hypothesis that cannot be totally discarded is the possibility of occurrence of clonal reproduction in the hermaphroditic species, although there is no known biological mechanism by which these species could propagate clonally on an exposed shore. This hypothesis is less likely 
because negative $F_{\text {IS }}$ values would be expected for populations with clonal reproduction (Balloux et al., 2003) and the potential for clonal reproduction has never been shown on exposed shores, only in highly sheltered subtidal habitats where vegetative fragments of Fucus spp. are able to settle for long time periods (Tatarenkov et al., 2005; Johannesson et al., 2011). Still, the hypothesis of high selfing rates has several consequences that are similar to clonality yet result in highly positive $F_{\text {IS }}$ as observed here.

An alternative explanation for the different levels of genetic structure observed between species and particularly the pattern of allele fixation in F. spiralis could be the potential role of height on the shore. Previous studies have found significant differences in genetic structure according to zonation patterns in the intertidal habitat (Engel et al., 2004; Kelly and Palumbi, 2010; Valero et al., 2011; Krueger-Hadfield et al., 2013). And some have found an increase in species' genetic structure with a decreasing height on the shore (Innes, 1988; Marko, 2004). This was suggested to be related to greater exposure to abiotic stress in the high shore, which particularly during glacial periods could have determined changes in intertidal assemblages by favoring the persistence of low-shore species over upper-intertidal ones (Marko, 2004). On the other hand, a greater adaptation of lowshore species to seawater physical properties could determine the higher differentiation between locations (Innes, 1988). This region is characterized by wide tidal amplitude (Garreau, 1993) and particularly $F$. spiralis has been found to occur in a narrow band (F. spiralis-High in Billard et al., 2010; Zardi et al., 2011), high above the mid-tide point $(2.5 \mathrm{~m})$ where a high percentage of time is spent emersed (78\%, Billard et al., 2010; 65-82\%, Zardi et al., 2011). Hence, greater exposure to abiotic stressors (desiccation, temperature) combined with limited gene flow due to selfing may promote adaptation to high shore ecophysiological conditions (i.e. resilience to air exposure) (e.g. Zardi et al., 2011). This could contribute to the allele fixation patterns observed in this study that may overcome processes favouring differentiation between populations. In contrast, $F$. vesiculosus occupies a wider vertical band along the intertidal and spends more time immersed (50\%, Billard et al., 2010; 31-63\%, Zardi et al., 2011), Additionally, the Brittany region has been suggested as a long term persistent refugial area for $F$. vesiculosus (Assis et al., 2014). Hence, local adaptation to hydrological conditions (e.g. sea surface temperature) combined with long persistence in this region could contribute to genetic divergence between regional units.

However, $F_{\mathrm{ST}}$ estimates for $F$. spiralis revealed quite high values for pairwise comparisons with population of St. Malo (Table 2A). This could possibly be related with the lack of within-population variability, a factor known to affect $F_{\text {ST }}$ estimates (Slatkin, 1995; reviewed in Meirmans and Hedrick, 2011).

Additionally, patterns of genetic structure for hermaphroditic species could also be directly influenced by the microsatellites used in this study. The set of microsatellites was chosen in order to allow comparison with previous studies (e.g. Coleman and Brawley, 2005; Engel et al., 2005; Billard et al., 2010). Other (potentially more informative) microsatellites specifically designed for $F$. spiralis (Perrin et al., 2007) could help to improve estimates of genetic parameters for the hermaphroditic species (Chakraborty et al., 1997; Ellegren, 2004; Engel et al., 2005). Additionally, higher number of populations sampled along the study region could improve the resolution and robustness of these results.

\subsection{Ecological implications}

The large increase in sea surface temperatures in the northeast Atlantic over the last twenty years, including this region, is predicted to continue (Hawkins et al., 2003; Mieszkowska et al., 2007; Gallon et al., 2014; Robuchon et al., 2014). Distribution limits of marine species are usually directly correlated with their thermal tolerance limits and responses to climate change are particularly strong (Blanchette et al., 2008; Sorte et al., 2010; Pinsky et al., 2013).

Biogeographic boundaries impose unique constraints for marine life that entail sharp changes in the genetic configuration, demographic parameters and distributional limits of species (Zacherl et al., 2003; Lima et al., 2007; Sivasundar and Palumbi, 2010). Alteration in physical factors responsible for the delimitation of biogeographic boundaries (e.g. sea surface temperature) are likely to have particularly important consequences on future distributions of sessile marine species with limited dispersal. Hence, the study of marine biota in these regions is essential to understand the coupling between physiological and life-history traits along with environmental variables, which may give valuable insights into their resilience capacity (Zacherl et al., 2003; Lima et al., 2007; Belanger et al., 2012). In particular, intertidal species that live close to upper temperature tolerance limits, are unique models to study the impact that climatic changes may have on species assemblages (reviewed in Helmuth et al., 2006; Somero, 2010).

Canopy-forming macroalgae are crucial for structuring rocky intertidal ecosystems and supporting complex food webs, and thus have a potentially huge impact on economically important species (Golléty et al., 2010; Kordas et al., 2011; Dijkstra et al., 2012). Temperature is known to be a factor determining the distribution of seaweeds, influencing survival, recruitment, growth and reproduction (Eggert, 2012; reviewed in Harley et al., 2012). Shifts in distributional ranges have already been observed for a number of species in recent years (Lima et al., 2006, 2007; Wernberg et al., 2011; Gallon et al., 2014) and many more are predicted to occur (Müller et al., 2009; Jueterbock et al., 2013). We found low levels of genetic diversity for highly selfing species, $F$. spiralis and $F$. guiryi. These may be locally adapted to more strict physical conditions (e.g. on the coast of Portugal, southern populations of $F$. vesiculosus showed a higher resilience to heat stress than northern populations, Saada et al., 2016). However, reduced genetic diversity due to low effective population size may render these populations highly vulnerable since stochastic events (i.e. genetic drift) could eliminate important traits of ecological and/or physiological relevance, resulting in a reduced capacity to respond to environmental stressors (Stockwell et al., 2003; Pujol and Pannell, 2008). For the species considered in this study, F. spiralis, which displays the lowest genetic diversity, also has the most restricted distribution south of this region and may potentially be the most vulnerable. Hence, studies of marine genetic diversity are essential in order to track changes and understand consequences of climate changes. Specifically, multi-species studies where different life-history traits may be considered in regions exhibiting environmental variation are important in 
order to investigate the link between biotic and abiotic factors determining species persistence in order to predict future impacts (Poloczanska et al., 2013; Mieszkowska et al., 2014). This approach could contribute to a clear view of conservation priorities and help in designing frameworks for active management and future research (e.g. Williams et al., 2008; Hoffmann et al., 2015).

\section{Conclusions}

Fucus vesiculosus showed genetic differentiation between the northern and the southern populations, in accordance with the hypothesis raised based on the oceanographic discontinuity of this region, but this pattern was not observed for the hermaphroditic species. Mating systems appeared to be determinant concerning population genetic variability and structure for this region, more than the physical abiotic differences prevailing in this region. Distinct levels of genetic diversity between the hermaphroditic Fucus spiralis, F. guiryi and the dioecious $F$. vesiculosus were found to be consistent with the mating system displayed by the species. Alternatively, possible effects related to altitude on the shore along with biogeographic history may be determinant on the current emergent patterns.

\section{Supplementary Material}

Figure S1. Null allele frequency for all loci for (A) Fucus spiralis, (B) F. guiryi and (C) F. vesiculosus. Dots correspond to the mean frequency across populations for each locus calculated using Estimator 1 from Brookfield (1996). Vertical bars represent the standard deviation for the estimated values.

Figure S2. Allelic frequencies for Fucus spiralis, F. guiryi and $F$. vesiculosus, for each locus and location. Dots of varying diameter represent the frequency of the allele classes indicated below. Codes correspond to locations in Table 1.

Figure S3. Magnitude of $\Delta K$ as a function of $K$ for $F$. vesiculosus. The modal value of $\Delta K$ that is based on the rate of change in the log probability of data between successive $K$ values is considered as the highest level of population structuring.

Table S1. PCR conditions. Mixture and program for the microsatellites amplified following Engel et al. (2003) for L20, L38, L58, L78, L94; Wallace et al. (2004) for F26II; Coyer et al. (2009) for F42. $\left(^{*}\right)$ indicates a touchdown step: decrease in $0.2^{\circ} \mathrm{C}$ per cycle.

Table S2. Pairwise genetic differentiation for (A) Fucus spiralis, (B) $F$. guiryi and (C) F. vesiculosus. Mean values of $F_{\mathrm{ST}}$ with the estimator $\theta$ are reported above the diagonal, while mean $D_{\text {Jost }}$ values are reported below the diagonal. $95 \%$ confidence intervals are in brackets. Codes correspond to locations in Table 1.

The Supplementary Material is available at http://www. alr-journal.org/10.1051/alr/2017012/olm.
Acknowledgements. This research was funded by projects CCMAR - UID/MULTI/04326/2013, EXCL/AAG-GLO/ 0661/2012, and IF/01413/2014/CP1217/CT0004 from the Fundação para a Ciência e a Tecnologia (FCT-MEC, Portugal). The authors thank Joana Ferreira Costa for helping with genotyping work and anonymous reviewers for their comments and suggestions.

\section{References}

Alberto F. 2009. MsatAllele 1.0: an R package to visualize the binning of microsatellite alleles. J Hered 100: 394-397.

Alberto F, Arnaud-Haond S, Duarte CM, Serrão EA. 2006. Genetic diversity of a clonal angiosperm near its range limit: the case of Cymodocea nodosa at the Canary Islands. Mar Ecol Prog Ser 309: 117-129.

Assis J, Serrão EA, Claro B, Perrin C, Pearson GA. 2014. Climatedriven range shifts explain the distribution of extant gene pools and predict future loss of unique lineages in a marine brown alga. Mol Ecol 23: 2797-2810.

Ayata SD, Lazure P, Thiébaut É, 2010. How does the connectivity between populations mediate range limits of marine invertebrates? A case study of larval dispersal between the Bay of Biscay and the English Channel (North-East Atlantic). Prog Oceanogr 87(1): 18 36.

Ayata SD, Stolba R, Comtet T, Thiébaut E. 2011. Meroplankton distribution and its relationship to coastal mesoscale hydrological structure in the northern Bay of Biscay (NE Atlantic). J Plankton Res 33: 1193-1211.

Balloux F, Lehmann L, de Meeûs T. 2003. The population genetics of clonal and partially clonal diploids. Genetics 164(4): 16351644.

Belanger CL, Jablonski D, Roy K, Berke SK, Krug AZ, Valentine JW. 2012. Global environmental predictors of benthic marine biogeographic structure. Proc Natl Acad Sci U S A 109(35): 14046-14051.

Belkhir K, Borsa P, Chikhi L, Raufaste N, Bonhomme F. 2004. GENETIX 4.05, Population genetics software for Windows TM. France: Université de Montpellier II, Montpellier.

Benjamini Y, Hochberg Y. 1995. Controlling the false discovery rate: a practical and powerful approach to multiple testing. J R Stat Soc Ser B 57: 289-300.

Billard E, Serrão E, Pearson G, Destombe C, Valero M. 2010. Fucus vesiculosus and spiralis species complex: a nested model of local adaptation at the shore level. Mar Ecol Prog Ser 405: 163-174.

Billot C, Engel CR, Rousvoal S, Kloareg B, Valero M. 2003. Current patterns, habitat discontinuities and population genetic structure: the case of the kelp Laminaria digitata in the English Channel. Mar Ecol Prog Ser 253: 111-121.

Blanchette CA, Miner CM, Raimondi PT, Lohse D, Heady KE, Broitman BR. 2008. Biogeographical patterns of rocky intertidal communities along the Pacific coast of North America. J Biogeogr 35(9): 1593-1607.

Breeman AM. 1988. Relative importance of temperature and other factors in determining geographic boundaries of seaweeds: experimental and phenological evidence. Helgol Meeresunters 42(2): 199-241.

Cánovas FG, Mota CF, Serrão EA, Pearson GA. 2011. Driving south: a multi-gene phylogeny of the brown algal family Fucaceae reveals relationships and recent drivers of a marine radiation. $B M C$ Evol Biol 11(1): 1. 
Chakraborty R, Kimmel M, Stivers DN, Davison LJ, Deka R. 1997. Relative mutation rates at di-, tri-, and tetranucleotide microsatellite loci. Proc Natl Acad Sci U S A 94(3): 1041-1046.

Chapuis MP, Estoup A. 2007. Microsatellite null alleles and estimation of population differentiation. Mol Biol Evol 24: 621-631.

Chybicki IJ, Burczyk J. 2009. Simultaneous estimation of null alleles and inbreeding coefficients. J Hered 100(1): 106-113.

Coleman MA, Brawley SH. 2005. Are life history characteristics good predictors of genetic diversity and structure? A case study of the intertidal alga Fucus spiralis (Heterokontophyta; Phaeophyceae). J Phycol 41(4): 753-762.

Couceiro L, Robuchon M, Destombe C, Valero M. 2013. Management and conservation of the kelp species Laminaria digitata: using genetic tools to explore the potential exporting role of the MPA "Parc naturel marin d'Iroise". Aquat Living Resour 26: 197205.

Coyer JA, Hoarau G, Oudot-Le Secq MP, Stam WT, Olsen JL. 2006. A mtDNA based phylogeny of the brown algal genus Fucus (Heterokontophyta; Phaeophyta). Mol Phylogenetics Evol 39: 209-222.

Coyer JA, Hoarau G, Beszteri B, Pearson G, Olsen JL. 2009. Expressed sequence tag-derived polymorphic SSR markers for Fucus serratus and amplification in other species of Fucus. Mol Ecol Res 9: 168-170.

Dakin EE, Avise JC. 2004. Microsatellite null alleles in parentage analysis. Hered 93(5): 504-509.

Dawson MN. 2001. Phylogeography in coastal marine animals: a solution from California? J Biogeogr 28(6): 723-736.

Dharmarajan G, Beatty WS, Rhodes OE. 2013. Heterozygote deficiencies caused by a Wahlund effect: dispelling unfounded expectations. J Wildl Manage 77(2): 226-234.

Dijkstra JA, Boudreau J, Dionne M. 2012. Species-specific mediation of temperature and community interactions by multiple foundation species. Oikos 121(5): 646-654.

Earl DA, von Holdt BM. 2012. STRUCTURE HARVESTER: a website and program for visualizing STRUCTURE output and implementing the Evanno method. Conserv Genet Resour 4(2): 359-361.

Eggert A. 2012. Seaweed responses to temperature. In: Seaweed biology. Berlin Heidelberg: Springer, pp. 47-66.

Ellegren H. 2004. Microsatellites: simple sequences with complex evolution. Nat Rev Genet 5(6): 435-445.

Engel CR, Brawley SH, Edwards KJ, Serrão EA. 2003. Isolation and cross-species amplification of microsatellite loci from the fucoid seaweeds Fucus vesiculosus, F. serratus and Ascophyllum nodosum (Heterokontophyta, Fucaceae). Mol Ecol Notes 3: 180-182.

Engel CR, Destombe C, Valero M. 2004. Mating system and gene flow in the red seaweed Gracilaria gracilis: effect of haploiddiploid life history and intertidal rocky shore landscape on finescale genetic structure. Heredity 92(4): 289-298.

Engel CR, Daguin C, Serrão EA. 2005. Genetic entities and mating system in hermaphroditic Fucus spiralis and its close dioecious relative $F$. vesiculosus (Fucaceae, Phaeophyceae). Mol Ecol 14: 2033-2046.

Evanno G, Regnaut S, Goudet J, 2005. Detecting the number of clusters of individuals using the software STRUCTURE: a simulation study. Mol Ecol 14: 2611-2620.

Gallon RK, Robuchon M, Leroy B, Le Gall L, Valero M, Feunteun E. 2014. Twenty years of observed and predicted changes in subtidal red seaweed assemblages along a biogeographical transition zone: inferring potential causes from environmental data. J Biogeogr 41 : 2293-2306.
Garreau P. 1993. Hydrodynamics of the north brittany coast - a synoptic study. Oceanol Acta 16(5-6): 469-477.

Gerlach G, Jueterbock A, Kraemer P, Deppermann J, Harmand P. 2010. Calculations of population differentiation based on G(ST) and D: forget G(ST) but not all of statistics! Mol Ecol 19: 3845-3852.

Gilg MR, Hilbish TJ. 2003. The geography of marine larval dispersal: coupling genetics with fine-scale physical oceanography. Ecology 84: 2989-2998.

Goldson AJ, Hughes RN, Gliddon CJ. 2001. Population genetic consequences of larval dispersal mode and hydrography: a case study with bryozoans. Mar Biol 138(5): 1037-1042.

Golléty C, Riera P, Davoult D. 2010. Complexity of the food web structure of the Ascophyllum nodosum zone evidenced by a $\delta^{13} \mathrm{C}$ and $\delta^{15} \mathrm{~N}$ study. J Sea Res 64(3): 304-312.

Guillemin ML, Valero M, Tellier F, Macaya EC, Destombe C, Faugeron S. 2016. Phylogeography of seaweeds in the South East Pacific: complex evolutionary processes along a latitudinal gradient. In: Hu ZM, Fraser C, eds. Seaweed phylogeography. Netherlands: Springer, pp. 251-277.

Hawkins SJ, Southward AJ, Genner MJ. 2003. Detection of environmental change in a marine ecosystem - evidence from the western English Channel. Sci Total Environ 310(1): 245-256.

Harley CD, Anderson KM, Demes KW, et al. 2012. Effects of climate change on global seaweed communities. $J$ Phycol 48(5): 1064-1078.

Haye PA, Segovia NI, Muñoz-Herrera NC, et al. 2014. Phylogeographic structure in benthic marine invertebrates of the southeast Pacific coast of Chile with differing dispersal potential. PLOS ONE 9(2): e88613.

Helmuth B, Mieszkowska N, Moore P, Hawkins SJ. 2006. Living on the edge of two changing worlds: forecasting the responses of rocky intertidal ecosystems to climate change. Annu Rev Ecol Evol Syst 37: 373-404.

Hoarau G, Coyer JA, Veldsink JH, Stam WT, Olsen JL. 2007a. Glacial refugia and recolonization pathways in the brown seaweed Fucus serratus. Mol Ecol 16: 3606-3616.

Hoarau G, Coyer JA, Stam WT, Olsen JL. 2007b. A fast and inexpensive DNA extraction/purification protocol for brown macroalgae. Mol Ecol Notes 7: 3606-3616.

Hoffmann A, Griffin P, Dillon S, et al. 2015. A framework for incorporating evolutionary genomics into biodiversity conservation and management. Clim Chang Responses 2(1): 1.

Innes DJ. 1988. Genetic differentiation in the intertidal zone in populations of the alga Enteromorpha linza (Ulvales: Chlorophyta). Mar Biol 97(1): 9-16.

Johannesson K, Johansson D, Larsson KH, et al. 2011. Frequent clonality in fucoids (Fucus radicans and Fucus vesiculosus; Fucales, Phaeophyceae) in the Baltic Sea. J Phycol 47(5): 990-998.

Jolly MT, Jollivet D, Gentil F, Thiébaut E, Viard F. 2005. Sharp genetic break between Atlantic and English Channel populations of the polychaete Pectinaria koreni, along the north coast of France. Heredity 94: 23-32.

Johnson MS, Black R. 1984. The Wahlund effect and the geographical scale of variation in the intertidal limpet Siphonaria sp. Mar Biol 79(3): 295-302.

Jueterbock A, Tyberghein L, Verbruggen H, Coyer JA, Olsen JL, Hoarau G. 2013. Climate change impact on seaweed meadow distribution in the North Atlantic rocky intertidal. Ecol Evol 3(5): 1356-1373.

Keenan K, McGinnity P, Cross TF, Crozier WW, Prodohl PA. 2013. diveRsity: an $\mathrm{R}$ package for the estimation and exploration of population genetics parameters and their associated errors. Methods Ecol Evol 4: 782-788. 
Kelly RP, Palumbi SR. 2010. Genetic structure among 50 species of the northeastern Pacific rocky intertidal community. PLoS ONE 5(1): e8594.

Kordas RL, Harley CD, O’Connor MI. 2011. Community ecology in a warming world: the influence of temperature on interspecific interactions in marine systems. J Exp Mar Biol Ecol 400(1): 218-226.

Krueger-Hadfield SA, Roze D, Mauger S, Valero M. 2013. Intergametophytic selfing and microgeographic genetic structure shape populations of the intertidal red seaweed Chondrus crispus. Mol Ecol 22(12): 3242-3260.

Ladah LB, Bermudez R, Pearson GA, Serrão EA. 2003. Fertilization success and recruitment of dioecious and hermaphroditic fucoid seaweeds with contrasting distributions near their southern limit. Mar Ecol Prog Ser 262: 173-183.

Leys M, Petit EJ, El-Bahloul Y, Liso C, Fournet S, Arnaud JF. 2014. Spatial genetic structure in Beta vulgaris subsp. maritima and Beta macrocarpa reveals the effect of contrasting mating system, influence of marine currents, and footprints of postglacial recolonization routes. Ecol Evol 4(10): 1828-1852.

Lima FP, Queiroz N, Ribeiro PA, Hawkins SJ, Santos AM. 2006. Recent changes in the distribution of a marine gastropod, Patella rustica Linnaeus, 1758, and their relationship to unusual climatic events. J Biogeogr 33(5): 812-822.

Lima FP, Ribeiro PA, Queiroz N, Hawkins SJ, Santos AM. 2007. Do distributional shifts of northern and southern species of algae match the warming pattern? Glob Chang Biol 13: 25922604.

Lourenço CR, Zardi GI, McQuaid CD, et al. 2016. Upwelling areas as climate change refugia for the distribution and genetic diversity of a marine macroalga. J Biogeogr 43: 1595-1607.

Lüning K. 1990. Seawe eds their environment, biogeography and ecophysiology. New York: Wiley.

Jost L. 2008. G $\mathrm{G}_{\mathrm{ST}}$ and its relatives do not measure differentiation. Mol Ecol 17(18): 4015-4026.

Marko PB. 2004. 'What's larvae got to do with it?' Disparate patterns of post-glacial population structure in two benthic marine gastropods with identical dispersal potential. Mol Ecol 13(3): 597-611.

Martinez B, Viejo RM, Carreño F, Aranda SC. 2012. Habitat distribution models for intertidal seaweeds: responses to climatic and non-climatic drivers. J Biogeogr 39: 1877-1890.

Meirmans PG, Hedrick PW. 2011. Assessing population structure: $F_{\mathrm{ST}}$ and related measures. Mol Ecol Resour 11(1): 5-18.

Mieszkowska N, Sugden HE. 2016. Climate-driven range shifts within benthic habitats across a marine biogeographic transition zone. Adv Ecol Res 55: 325-369.

Mieszkowska N, Hawkins SJ, Burrows MT, Kendall MA. 2007. Long-term changes in the geographic distribution and population structures of Osilinus lineatus (Gastropoda: Trochidae) in Britain and Ireland. J Mar Biol Assoc UK 87(2): 537-545.

Mieszkowska N, Sugden H, Firth LB, Hawkins SJ. 2014. The role of sustained observations in tracking impacts of environmental change on marine biodiversity and ecosystems. Philos Trans $R$ Soc Lond A: Math Phys Eng Sci 372(2025): 20130339.

Monteiro CA, Serrão EA, Pearson GA. 2012. Prezygotic barriers to hybridization in marine broadcast spawners: reproductive timing and mating system variation. PLoS ONE 7(4): e35978.

Monteiro CA, Paulino C, Jacinto R, Serrão EA, Pearson GA. 2016. Temporal windows of reproductive opportunity reinforce species barriers in a marine broadcast spawning assemblage. Sci Rep 6: 29198.
Muhlin JF, Brawley SH. 2009. Recent versus relic: discerning the genetic signature of Fucus vesiculosus (Heterokontophyta; Phaeophyceae) in the northwestern Atlantic. Phycol Soc Am 837: 828-837.

Muhlin JF, Engel CR, Stessel R, Weatherbee RA, Brawley SH. 2008. The influence of coastal topography, circulation patterns, and rafting in structuring populations of an intertidal alga. Mol Ecol 17: $1198-1210$.

Müller R, Laepple T, Bartsch I, Wiencke C. 2009. Impact of oceanic warming on the distribution of seaweeds in polar and coldtemperate waters. Bot Mar 52(6): 617-638.

Nei M. 1978. Estimation of average heterozygosity and genetic distance from a small number of individuals. Genetics 89: 583590.

Neiva J, Pearson GA, Valero M, Serrão EA. 2012. Fine-scale genetic breaks driven by historical range dynamics and ongoing densitybarrier effects in the estuarine seaweed Fucus ceranoides L. BMC Evol Biol 12: 78.

Neiva J, Serrão EA, Assis J, et al. 2016. Climate oscillations, range shifts and phylogeographic patterns of North Atlantic Fucaceae. In: Hu ZM, Fraser C, eds. Seaweed phylogeography. Netherlands: Springer, pp. 279-308.

Nicastro KR, Zardi GI, Teixeira S, Neiva J, Serrão EA, Pearson GA. 2013. Shift happens: trailing edge contraction associated with recent warming trends threatens a distinct genetic lineage in the marine macroalga Fucus vesiculosus. BMC Biol 11: 6 .

Perrin C, Daguin C, van de Vliet M, Engel CR, Pearson GA, Serrão EA. 2007. Implications of mating system for genetic diversity of sister algal species: Fucus spiralis and Fucus vesiculosus (Heterokontophyta, Phaeophyceae). Eur J Phycol 42: 219-230.

Pinsky ML, Worm B, Fogarty MJ, Sarmiento JL, Levin SA. 2013. Marine taxa track local climate velocities. Science 341(6151): $1239-1242$.

Poloczanska ES, Brown CJ, Sydeman WJ, et al. 2013. Global imprint of climate change on marine life. Nat Clim Chang 3(10): 919-925.

Pritchard JK, Stephens M, Donnelly P. 2000. Inference of population structure using multilocus genotype data. Genetics 155: 945-959.

Provan J. 2013. The effects of past, present and future climate change on range-wide genetic diversity in northern North Atlantic marine species. Front Biogeogr 5(1).

Puillat I, Lazure P, Jégou AM, Lampert L, Miller P. 2004. Hydrographical variability on the French continental shelf of the Bay of Biscay during the 1190s. Cont Shelf Res 24: 1143-1163.

Puillat I, Lazure P, Jégou AM, Lampert L, Miller P. 2006. Mesoscale hydrological variability induced by northwesterly wind of the French continental shelf of the Bay of Biscay. Sci Mar 70: 15-26.

Pujol B, Pannell JR. 2008. Reduced responses to selection after species range expansion. Science 321(5885): 96-96.

Pujol B, Zhou SR, Vilas JS, Pannell JR. 2009. Reduced inbreeding depression after species range expansion. Proc Natl Acad Sci US A 106(36): 15379-15383.

Robuchon M, Le Gall L, Mauger S, Valero M. 2014. Contrasting genetic diversity patterns in two sister kelp species co-distributed along the coast of Brittany, France. Mol Ecol 23(11): 2669-2685.

Saada G, Nicastro KR, Jacinto R, et al. 2016. Taking the heat: distinct vulnerability to thermal stress of central and threatened peripheral lineages of a marine macroalga. Divers Distrib 22(10): 1060 1068 .

Salomon JC, Breton M. 1993. An atlas of long term currents in the Channel. Oceanol Acta 16: 439-448.

Selkoe KA, Watson JR, White C, et al. 2010. Taking the chaos out of genetic patchiness: seascape genetics reveals ecological and 
oceanographic drivers of genetic patterns in three temperate reef species. Mol Ecol 19: 3708-3726.

Serrão EA, Kautsky L, Lifvergren T, Brawley SH. 1997. Gamete dispersal and pre-recruitment mortality in Baltic Fucus vesiculosus. Phycology 36: 101-102.

Sivasundar A, Palumbi SR. 2010. Life history, ecology and the biogeography of strong genetic breaks among 15 species of Pacific rockfish, Sebastes. Mar Biol 157(7): 1433-1452.

Slatkin M. 1995. A measure of population subdivision based on microsatellite allele frequencies. Genetics 139(1): 457-462.

Somero GN. 2010. The physiology of climate change: how potentials for acclimatization and genetic adaptation will determine 'winners' and 'losers'. J Exp Biol 213(6): 912-920.

Sorte CJ, Williams SL, Carlton JT. 2010. Marine range shifts and species introductions: comparative spread rates and community impacts. Glob Ecol Biogeogr 19(3): 303-316.

Spalding MD, Fox HE, Allen GR, et al. 2007. Marine ecoregions of the world: a bioregionalization of coastal and shelf areas. BioScience 57: 573-583.

Stockwell CA, Hendry AP, Kinnison MT. 2003. Contemporary evolution meets conservation biology. Trends Ecol Evol 18(2): 94-101.

Storey JD. 2002. A direct approach to false discovery rates. J R Stat Soc Ser B Stat Methodol 64: 479-498.

Tatarenkov A, Bergström L, Jönsson RB, Serrão EA, Kautsky L, Johannesson K. 2005. Intriguing asexual life in marginal populations of the brown seaweed Fucus vesiculosus. Mol Ecol 14(2): 647-651.

Teixeira S, Pearson GA, Candeias R, Madeira C, Valero M, Serrão, EA. 2016. Lack of fine-scale genetic structure and distant mating in natural populations of Fucus vesiculosus. Mar Ecol Prog Ser 544: 131-142.

Tellier F, Meynard AP, Correa JA, Faugeron S, Valero M. 2009. Phylogeographic analyses of the $30^{\circ} \mathrm{S}$ south-east Pacific biogeographic transition zone establish the occurrence of a sharp genetic discontinuity in the kelp Lessonia nigrescens: Vicariance or parapatry? Mol Phylogenetics Evol 53(3): 679-693.

Toonen RJ, Hughes S. 2001. Increased Throughput for Fragment Analysis on ABI Prism 377 Automated Sequencer Using a Membrane Comb and STRand Software. Biotechniques 31: 1320-1324.
Valero M, Destombe C, Mauger S, et al. 2011. Using genetic tools for sustainable management of kelps: a literature review and the example of Laminaria digitata. Cah Biol Mar 52(4): 467.

van Oosterhout C, Hutchinson WF, Wills DPM, Shipley P. 2004. Micro-checker: software for identifying and correcting genotyping errors in microsatellite data. Mol Ecol Notes 4: 535-538.

Wallace AR, Klein AS, Mathieson AC. 2004. Determining the affinities of salt marsh fucoids using microsatellite markers: evidence of hybridization and introgression between two species of Fucus (Phaeophyceae) in a Maine estuary. J Phycol 40: 1013-1027.

Weir B, Cockerham C, 1984. Estimating $F$-statistics for the analysis of population structure. Evolution 38(6): 1358-1370.

Wernberg T, Russell BD, Thomsen MS, et al. 2011. Seaweed communities in retreat from ocean warming. Curr Biol 21(21): 1828-1832.

Williams ST, Benzie JAH. 1998. Evidence of a biogeographic break between populations of a high dispersal starfish: congruent regions within the Indo-West Pacific defined by color morphs, mtDNA, and allozyme data. Evolution: 87-99.

Williams SE, Shoo LP, Isaac JL, Hoffmann AA, Langham G. 2008. Towards an integrated framework for assessing the vulnerability of species to climate change. PLoS Biol 6(12): e325.

Zacherl D, Gaines SD, Lonhart SI. 2003. The limits to biogeographical distributions: insights from the northward range extension of the marine snail, Kelletia kelletii (Forbes, 1852). J Biogeogr 30(6): 913-924.

Zardi GI, Nicastro KR, Cánovas F, Costa JF, Serrão EA, Pearson GA. 2011. Adaptive traits are maintained on steep selective gradients despite gene flow and hybridization in the intertidal zone. PLoS ONE 6(6): e19402.

Zardi GI, Nicastro KR, McQuaid CD, et al. 2015a. Intraspecific genetic lineages of a marine mussel show behavioural divergence and spatial segregation over a tropical/subtropical biogeographic transition. BMC Evol Biol 15(1): 100.

Zardi GI, Nicastro KR, Serrão EA, Jacinto R, Monteiro CA, Pearson GA. 2015b. Closer to the rear edge: ecology and genetic diversity down the core-edge gradient of a marine macroalga. Ecosphere 6(2): $1-25$.

Cite this article as: Almeida SC, Nicastro KR, Zardi GI, Pearson GA, Valero M, Serrão EA. 2017. Reproductive strategies and population genetic structure of Fucus spp. across a northeast Atlantic biogeographic transition. Aquat. Living Resour. 30 : 16 